\title{
Psychological processes underlying the association between childhood trauma and psychosis in daily life: an experience sampling study
}

\author{
U. Reininghaus ${ }^{1,2 *}$, C. Gayer-Anderson ${ }^{2}$, L. Valmaggia ${ }^{3}$, M. J. Kempton ${ }^{4}$, M. Calem ${ }^{4}$, A. Onyejiaka ${ }^{3}$, \\ K. Hubbard ${ }^{2}$, P. Dazzan ${ }^{4,5}$, S. Beards², H. L. Fisher ${ }^{6}$, J. G. Mills ${ }^{4}$, P. McGuire, ${ }^{4,5}$, T. K. J. Craig' ${ }^{2}$, \\ P. Garety ${ }^{3}$, J. van Os ${ }^{1,4}$, R. M. Murray ${ }^{4,5}$, T. Wykes ${ }^{3,5}$, I. Myin-Germeys ${ }^{7}$ and C. Morgan ${ }^{2,5}$ \\ ${ }^{1}$ Department of Psychiatry and Psychology, School for Mental Health and Neuroscience, Maastricht University, Maastricht, The Netherlands \\ ${ }^{2}$ Health Service and Population Research Department, Centre for Epidemiology and Public Health, Institute of Psychiatry, Psychology \& \\ Neuroscience, King's College London, London, UK \\ ${ }^{3}$ Psychology Department, Institute of Psychiatry, Psychology \& Neuroscience, King's College, London, UK \\ ${ }^{4}$ Psychosis Studies Department, Institute of Psychiatry, Psychology \& Neuroscience, King's College, London, UK \\ ${ }^{5}$ National Institute for Health Research (NIHR) Mental Health Biomedical Research Centre (BRC) at South London and Maudsley NHS Foundation \\ Trust and King's College London, London, UK \\ ${ }^{6}$ MRC Social, Genetic \& Developmental Psychiatry Centre, Institute of Psychiatry, Psychology E Neuroscience, King's College London, London, UK \\ ${ }^{7}$ Department of Medicine, Psychiatry Research Group, Catholic University of Leuven, Leuven, Belgium
}

Background. Evidence has accumulated that implicates childhood trauma in the aetiology of psychosis, but our understanding of the putative psychological processes and mechanisms through which childhood trauma impacts on individuals and contributes to the development of psychosis remains limited. We aimed to investigate whether stress sensitivity and threat anticipation underlie the association between childhood abuse and psychosis.

Method. We used the Experience Sampling Method to measure stress, threat anticipation, negative affect, and psychotic experiences in 50 first-episode psychosis (FEP) patients, 44 At-Risk Mental State (ARMS) participants, and 52 controls. Childhood abuse was assessed using the Childhood Trauma Questionnaire.

Results. Associations of minor socio-environmental stress in daily life with negative affect and psychotic experiences were modified by sexual abuse and group (all $p_{\mathrm{FWE}}<0.05$ ). While there was strong evidence that these associations were greater in FEP exposed to high levels of sexual abuse, and some evidence of greater associations in ARMS exposed to high levels of sexual abuse, controls exposed to high levels of sexual abuse were more resilient and reported less intense negative emotional reactions to socio-environmental stress. A similar pattern was evident for threat anticipation.

Conclusions. Elevated sensitivity and lack of resilience to socio-environmental stress and enhanced threat anticipation in daily life may be important psychological processes underlying the association between childhood sexual abuse and psychosis.

Received 18 December 2015; Revised 20 May 2016; Accepted 24 May 2016; First published online 12 July 2016

Key words: Childhood abuse, ecological momentary assessment, first-episode psychosis, mechanism, prodrome, resilience, stress sensitivity, threat anticipation.

\section{Introduction}

Over the past decade, evidence has accumulated that implicates childhood trauma in the aetiology of psychosis. Childhood trauma refers to a range of early negative and potentially harmful experiences including sexual, physical and emotional abuse (Morgan \& Fisher, 2007). Findings from a modest number of epidemiological studies suggest childhood trauma confers

\footnotetext{
* Address for correspondence: Dr U. Reininghaus, Department of Psychiatry and Neuropsychology, School for Mental Health and Neuroscience, Faculty of Health, Medicine and Life Sciences, Maastricht University, P.O. Box 616 (VIJV1), 6200 MD Maastricht, The Netherlands.

(Email: u.reininghaus@maastrichtuniversity.nl)
}

risk of experiencing psychotic symptoms (Morgan \& Fisher, 2007; Varese et al. 2012). While most studies to date have focused on the role of childhood sexual abuse (Morgan \& Fisher, 2007; Varese et al. 2012; Matheson et al. 2013), and some authors have argued that sexual and physical abuse are potent risk factors (Read et al. 2005; Bentall et al. 2014), emotional abuse has also been associated with an increased risk of psychosis (Varese et al. 2012).

Although we know there is an association between childhood abuse and psychosis, we know little about the psychological processes and mechanisms involved. Current models of psychosis suggest that exposure to trauma in childhood makes individuals more sensitive to subsequent adversity through enhanced stress sensitivity and threat anticipation (Myin-Germeys et al.

This is an Open Access article, distributed under the terms of the Creative Commons Attribution licence (http://creativecommons.org/licenses/by/4.0/), which permits unrestricted re-use, distribution, and reproduction in any medium, provided the original work is properly cited. 
2001; Morgan \& Hutchinson, 2010; Morgan et al. 2010, 2014; Howes \& Murray, 2014). This type of model is supported by an experience sampling study in general practice, which showed that individuals exposed to childhood physical and sexual abuse reported more intense negative emotional reactions to daily life stress (Glaser et al. 2006). Similar results have been found in responses to daily hassles in individuals with depression (Wichers et al. 2009) and enduring psychotic disorder (Lardinois et al. 2011).

Childhood trauma may increase sensitivity not only to minor stressful events but also to more minor adverse social contexts and experiences later in daily life, including distinctive unpleasant social situations (referred to here as 'social stress') (Myin-Germeys et al. 2001; Morgan et al. 2014), subjective experiences of outsider status (as one specific, potentially relevant form of social stress) (Morgan \& Fisher, 2007; Morgan et al. 2010; Gevonden et al. 2015), and unpleasant neighbourhoods (referred to here as 'area-related stress') (Jaffee et al. 2007; Kirkbride et al. 2014). Further, exposure to adverse and threatening experiences during childhood may lead individuals to anticipate more unpleasant events and threat from their environment to create an enduring sense of threat anticipation (Morgan et al. 2010; Bentall et al. 2014). The Experience Sampling Method (ESM) provides a context-sensitive approach to study whether childhood trauma may amplify threat anticipation as well as stress sensitivity and, thereby, contribute to the development of psychotic experiences in daily life. However, previous studies have not investigated this in individuals with first-episode psychosis (FEP) compared to individuals with an At-Risk Mental State (ARMS; also known as High-Risk or Ultra-High-Risk states) for psychosis (Yung et al. 2005; Fusar-Poli et al. 2013a), and controls. This would allow us to minimize bias due to the potential effects of illness chronicity and further elucidate the impact of putative psychological mechanisms across different stages in the development of psychosis.

Using data from an experience sampling study of FEP individuals, ARMS individuals, and controls with no personal or family history of psychosis, we aimed to investigate whether elevated stress sensitivity and enhanced threat anticipation are important psychological mechanisms underlying the association between childhood sexual, physical and emotional abuse and psychosis. We previously demonstrated in this sample that elevated stress sensitivity, characterized by intense emotional reactions to event-related stress, social stress, area-related stress and experiences of outsider status, as well as enhanced threat anticipation are important psychological processes in the development of psychotic experiences in daily life across different stages of subclinical, prodromal, and FEP (Reininghaus et al. 2016c). In the current study, we aimed to investigate whether associations of putative psychological mechanisms (event-related stress, social stress, area-related stress, experiences of outsider status, threat anticipation) with (i) negative affect and (ii) psychotic experiences were modified by prior exposure to childhood abuse (sexual, physical, and emotional abuse) and group (FEP, ARMS, controls). Specifically, we sought to test the following hypotheses: (1) within each group, the magnitude of associations of each psychological mechanism with (i) negative affect and (ii) psychotic experiences is greater in individuals exposed to high levels of abuse $v$. those exposed to low levels of abuse (or, in short, the responses to stress and threat anticipation are more pronounced in those exposed) [first set of hypotheses (H1)]; and (2) the difference in magnitude of associations of each putative psychological mechanism with (i) negative affect and (ii) psychotic experiences (put simply, the difference in responses to stress and threat anticipation) between those exposed to high levels and those exposed to low levels of abuse is greater in $(a)$ FEP than in controls, (b) ARMS than in controls, and (c) FEP than in ARMS [second set of hypotheses $(\mathrm{H} 2)]$.

\section{Method}

\section{Sample}

We recruited a sample of FEP individuals, ARMS individuals, and controls with no personal or family history of psychosis identified in the Childhood Adversity and Psychosis (CAPsy) study and the London centre of the European Network of National Networks studying Gene-Environment Interactions in Schizophrenia (EUGEI, 2014). Individuals with FEP were recruited from mental health services within defined catchment areas in South-East London, UK. ARMS individuals were recruited from Outreach and Support in South London (OASIS), a clinical service for people at high risk of psychosis provided by the South London and Maudsley NHS Foundation Trust (Fusar-Poli et al. 2013b), the West London Mental Health NHS Trust (WLMHT), and a community survey of General Practitioner (GP) practices. Controls were recruited using GP lists and the national postal address file as sampling frames. Inclusion and exclusion criteria for FEP, ARMS and controls are shown in Table 1.

\section{Data collection}

\section{Socio-demographic characteristics}

Data on age, gender, ethnicity, level of education, and employment status were collected using a modified 
Table 1. Inclusion and exclusion criteria for FEP, ARMS, and controls

\begin{tabular}{|c|c|}
\hline Sample & Inclusion/exclusion criteria \\
\hline \multicolumn{2}{|l|}{ FEP } \\
\hline Inclusion criteria & $\begin{array}{l}\text { - Aged 18-64 } \\
\text { - Resident within the defined catchment areas; presence of a first episode of psychosis [ICD-10 F20-F29, } \\
\text { F30-F33 diagnoses (WHO, 1992), based on the OPCRIT system (McGuffin et al. 1991; Reininghaus et al. } \\
\text { 2016a)] } \\
\text { - Adequate command of the English language to complete the assessments }\end{array}$ \\
\hline Exclusion criteria & $\begin{array}{l}\text { - Transient psychotic symptoms resulting from acute intoxication } \\
\text { - Psychotic symptoms precipitated by an organic cause }\end{array}$ \\
\hline \multicolumn{2}{|r|}{ ( } \\
\hline Inclusion criteria & $\begin{array}{l}\text { - Aged 18-35 } \\
\text { - Presence of an ARMS based on CAARMS (Yung et al. 2005) or the SPI-A (i.e. meeting the at-risk criterion } \\
\text { of cognitive-perceptive basic symptoms) (Schultze-Lutter et al. 2007, 2010, 2012; Klosterkotter et al. 2011; } \\
\text { Mills, 2014) } \\
\text { - Adequate command of the English language }\end{array}$ \\
\hline Exclusion criteria & $\begin{array}{l}\text { - Prior experience of a psychotic episode for more than one week as determined by the CAARMS and SCID } \\
\text { (First et al. 2002) } \\
\text { - Previous treatment with an antipsychotic for a psychotic episode } \\
\text { - IQ }<60 \text { as measured with an adapted version of the WAIS (Ryan et al. 1999; EU-GEI, 2014) }\end{array}$ \\
\hline \multicolumn{2}{|r|}{ 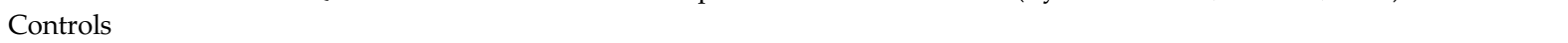 } \\
\hline Inclusion criteria & $\begin{array}{l}\text { - Aged } 18-64 \\
\text { - Resident within the same areas as FEP individuals } \\
\text { - Adequate command of the English language }\end{array}$ \\
\hline Exclusion criteria & $\begin{array}{l}\text { - Personal or family history of psychotic disorder (Maxwell, 1992) } \\
\text { - Presence of psychotic experiences, measured with the Psychosis Screening Questionnaire (Bebbington \& } \\
\text { Nayani, 1995) } \\
\text { - Presence of an ARMS based on the CAARMS or SPI-A }\end{array}$ \\
\hline
\end{tabular}

ARMS, At-Risk Mental State for psychosis; CAARMS, Comprehensive Assessment of At-Risk Mental States; FEP, first-episode psychosis; OPCRIT, Operational CRITeria system; SCID, Structured Clinical Interview for DSM Disorders; SOFAS, Social and Occupational Functioning Assessment Scale; SPI-A, Schizophrenia Proneness Instrument - Adult version; WAIS, Wechsler Adult Intelligence Scale.

a ARMS criteria based on the CAARMS (Yung et al. 2005; EU-GEI, 2014):

(1) Schizotypal personality disorder plus a recent decline in function [defined as (i) a 30\% drop in the SOFAS score (Goldman et al. 1992) from premorbid level, sustained for 1 month, and occurring within past 12 months; or (ii) a SOFAS score of $\leqslant 50$ for past $\geqslant 12$ months].

(2) First-degree relative with psychosis plus a recent decline in function (see above).

(3) 'Attenuated' positive psychotic symptoms.

(4) Brief psychotic episode of less than one week duration that resolves without antipsychotic medication.

version of the Medical Research Council (MRC) sociodemographic schedule (Mallet, 1997; EU-GEI, 2014).

\section{Sexual, physical and emotional abuse}

Sexual, physical and emotional abuse were measured using an established self-report measure, i.e. the Childhood Trauma Questionnaire (CTQ; Bernstein \& Fink, 1998), which measures the severity continuously with five items for each type of abuse before the age of 16. The CTQ asks participants to rate each item on a 5-point Likert scale ( $1=$ never true, $5=$ very often true) and allows computation of mean scores for each type of abuse ranging from 1 to 5 as well as categorical severity scores. Good psychometric properties have been reported for the CTQ in clinical as well as community samples (Scher et al. 2001; Wright et al. 2001).

\section{ESM measures}

Data on stress, threat anticipation, negative affect, and psychotic experiences were collected with ESM assessments scheduled at random within set blocks of time (Myin-Germeys et al. 2001, 2009; Shiffman et al. 2008; Palmier-Claus et al. 2011, 2012). Previous ESM research in samples of patients with psychotic disorder (Myin-Germeys et al. 2001; Lardinois et al. 2011), ARMS individuals (Palmier-Claus et al. 2012), and controls (Myin-Germeys et al. 2001; Palmier-Claus et al. 2012) has demonstrated the feasibility, reliability and 
validity of the assessment method (Myin-Germeys et al. 2009; Palmier-Claus et al. 2011). All participants were given an electronic momentary assessment technology device (the PsyMate ${ }^{\circledR}$, www.psymate.eu/) (Myin-Germeys et al. 2011). A detailed description of the ESM procedure and measures (Myin-Germeys et al. 2001, 2005; Delespaul et al. 2002; Corcoran et al. 2006; Bentall et al. 2008, 2009; Freeman et al. 2013) is shown in Table 2 and provided in Reininghaus et al. (2016c).

\section{Statistical analysis}

ESM data have a multilevel structure, such that multiple observations are nested within participants. In two-level, linear mixed models, multiple observations (level 1) were treated as nested within participants (level 2) using the 'xtmixed' command in Stata v. 13 (StataCorp., 2013). We fitted models with each putative psychological mechanism (event-related stress, social stress, area-related stress, experiences of outsider status, threat anticipation) as the continuous independent variable and (i) negative affect and (ii) psychotic experiences as the outcome variable, while controlling for potential confounders (i.e. age, gender, ethnicity, level of education, employment status). We added two-way (mechanism $\times$ abuse, mechanism $\times$ group, abuse $\times$ group) and three-way (mechanism $\times$ abuse $\times$ group) interactions to test whether associations between psychological mechanisms and (i) negative affect and (ii) psychotic experiences were modified by prior exposure to childhood abuse (continuous CTQ sexual, physical, and emotional abuse mean scores) and group (FEP, ARMS, controls). Likelihood ratio tests were used to evaluate improvement in model fit as well as the 'lincom' command to compute linear combinations of coefficients for testing the hypotheses that: (1) within each group, the magnitude of associations of each mechanism with (i) negative affect and (ii) psychotic experiences was greater in individuals exposed to high $v$. low levels of childhood abuse (mean \pm 1 S.D. of continuous CTQ scores) (Aiken \& West, 1991; Cohen et al. 2003) (H1); and (2) the difference in magnitude of associations of each mechanism with (i) negative affect and (ii) psychotic experiences in those exposed to high $v$. low levels of abuse was greater in (a) FEP than in controls, (b) ARMS than in controls, and (c) FEP than in ARMS (H2). We standardized continuous ESM and CTQ variables (mean=0, s.D. $=1$ ) for interpreting significant three-way interaction terms (Dawson \& Richter, 2006) and adjusted significance levels of likelihood ratio tests for three-way interactions to correct for Type-I error proliferation using family-wise error-corrected $p$ values ( $p_{\text {FWE }}$ ) computed by multiplying the unadjusted $p$ value by the total number of tests.

\section{Results}

\section{Basic sample characteristics}

During the study period, a total of 146 participants (50 FEP individuals, 44 ARMS individuals, and 52 controls) completed the CTQ and ESM assessment (with $\geqslant 20$ valid responses). ARMS and FEP individuals were younger, more often unemployed and educated to school level than controls (see Supplementary Table S1). FEP individuals reported on average higher levels of sexual $[B=0.32,95 \%$ confidence interval (CI) $0.003-0.64, p=0.048]$, physical $(B=0.34,95 \%$ CI 0.05 $0.63, p=0.022)$, and emotional $(B=0.53,95 \%$ CI $0.17-$ $0.88, p=0.004)$ abuse than controls. Levels of sexual abuse were similar in ARMS individuals and controls ( $B=0.14,95 \% \mathrm{CI}-0.20$ to $0.47, p=0.422)$. However, physical $(B=0.45,95 \%$ CI $0.15-0.75, p=0.004)$ and emotional $(B=1.06,95 \%$ CI $0.70-1.43, p<0.001)$ abuse levels were markedly elevated in ARMS individuals. While there was no evidence of marked differences in sexual $(B=0.19,95 \% \mathrm{CI}-0.15$ to $0.47, p=0.268)$ and physical $(B=-0.11,95 \% \mathrm{CI}-0.41$ to $0.19, p=$ 0.476) abuse across FEP and ARMS individuals, FEP individuals reported markedly lower levels of emotional abuse $(B=-0.54,95 \% \mathrm{CI}-0.90$ to $-0.17, p=$ 0.004) than ARMS individuals. In the ARMS group, 17 individuals had a SCID diagnosis of anxiety ( $n=$ $12)$, mood $(n=2)$, or mood and anxiety $(n=3)$ disorder.

\section{Psychological mechanisms underlying sexual abuse in FEP, ARMS, and controls}

As can be seen in Table 3, we found no evidence that the association between event-related stress and (i) negative affect and (ii) psychotic experiences was modified by prior exposure to childhood sexual abuse in FEP, ARMS, and controls. However, there was strong evidence for interaction effects (all $p_{\mathrm{FWE}}<0.05$ ) of social stress $\times$ sexual abuse $\times$ group, area-related stress $\times$ sexual abuse $\times$ group, outsider status $\times$ sexual abuse $\times$ group, and threat anticipation $\times$ sexual abuse $\times$ group on (i) negative affect and (ii) psychotic experiences. These indicated that the magnitude of associations of each psychological mechanism with (i) negative affect and (ii) psychotic experiences differed between high and low levels of abuse within (H1) and across (H2) groups as detailed in the following.

\section{FEP (H1)}

There was a greater association in FEP individuals exposed to high levels of sexual abuse than in FEP individuals exposed to low levels of sexual abuse between social stress (adj. $\beta_{\text {high } v \text {. low }}=0.11, p=0.005$ ), area-related stress (adj. $\beta_{\text {high } v \text {. low }}=0.20, p<0.001$ ), outsider status (adj. $\beta_{\text {high } v \text {. low }}=0.28, p<0.001$ ) and (i) 
Table 2. ESM procedure and measures of stress, negative affect, threat anticipation, and psychotic experiences

\begin{tabular}{|c|c|}
\hline Domain & ESM measure \\
\hline Stress & $\begin{array}{l}\text { Event-related and social stress was operationalized as minor disturbances and distinctive unpleasant events } \\
\text { and social situations that occur in the natural flow of daily life [based on previous ESM studies, in which } \\
\text { good internal consistency and concurrent validity with other stress measures have been reported } \\
\text { (Myin-Germeys et al. 2001; Palmier-Claus et al. 2011)] }\end{array}$ \\
\hline Event & $\begin{array}{l}\text { Event-related stress was measured with one item asking participants to rate the most important event since } \\
\text { the last beep on a 7-point Likert scale ranging from 'very unpleasant' (rating of -3) to 'very pleasant' } \\
\text { (rating of 3) (Myin-Germeys et al. 2001). We reversed the coding of this item in order for higher ratings to } \\
\text { indicate higher levels of stress (with ratings of }-3 \text { (i.e. 'very unpleasant') coded as } 7 \text { and ratings of } 3 \text { (i.e. } \\
\text { 'very pleasant') coded as 1) (Myin-Germeys et al. 2001) }\end{array}$ \\
\hline Social & $\begin{array}{l}\text { The ESM social stress measure we used consisted of two items to assess moments where an individual's } \\
\text { current social environment induces minor stress in the natural flow of daily life [based on previous ESM } \\
\text { studies (Myin-Germeys et al. 2001)]. Participants were first asked to indicate on a categorical item 'Who am } \\
\text { I with?' (partner, family, friends, colleagues, acquaintances, strangers, others, nobody) and then asked to } \\
\text { rate their current social context on a 7-point Likert scale ranging from 'not at all' (rating of 1) to 'very much' } \\
\text { (rating of 7)) using the following two items: (1) 'I would prefer to be alone [if with someone]/I would prefer } \\
\text { to have company [if alone]'; (2) 'I find being with these people pleasant [if with someone]/it is pleasant to } \\
\text { be alone [if alone]'. The coding of item } 2 \text { was reversed and the mean score of these two items computed as a } \\
\text { measure of minor social stress in daily life (Cronbach's } \alpha=0.62 \text { ) (Myin-Germeys et al. 2001) }\end{array}$ \\
\hline Area-related & $\begin{array}{l}\text { Area-related stress was assessed by asking participants to rate one item 'I find being in this neighbourhood } \\
\text { unpleasant' on a 7-point Likert scale }\end{array}$ \\
\hline Outsider status & $\begin{array}{l}\text { Based on previous research that suggests exposure to social adversity may sensitize individuals to subjective } \\
\text { experiences of outsider status as one potentially relevant form of social stress (Morgan \& Fisher, 2007; } \\
\text { Morgan } \text { et al. 2010; Gevonden } \text { et al. 2015), following ratings of current social context, participants were } \\
\text { asked to rate one item ('I feel I am an outsider') on a 7-point Likert scale to assess experiences of outsider } \\
\text { status. The association of this item with the ESM social }(r=0.33, p<0.001) \text { and area-related }(r=0.35, p< \\
\text { 0.001) stress measures indicated the item taps a distinct but related aspect of social stress and, overall, } \\
\text { reasonable concurrent validity }\end{array}$ \\
\hline Negative affect & $\begin{array}{l}\text { We used a 5-item ESM measure for assessing negative affect. This measure asks participants to rate the } \\
\text { following items at each entry point on a 7-point Likert scale: 'I feel anxious', 'I feel down', 'I feel lonely', 'I } \\
\text { feel insecure', and 'I feel annoyed' (Cronbach's } \alpha=0.86 \text { ) (Myin-Germeys et al. 2001) }\end{array}$ \\
\hline Threat anticipation & $\begin{array}{l}\text { Our ESM measure of threat anticipation was based on a self-report format used for assessing this } \\
\text { mechanism in previous cross-sectional studies asking participants to rate the likelihood of negative events } \\
\text { happening to them in the future (Corcoran et al. 2006; Bentall et al. 2008, 2009; Freeman } \text { et al. 2013). At each } \\
\text { entry point, participants were asked to think of what might happen in the next few hours and to rate the } \\
\text { item 'I think that something unpleasant will happen' on a 7-point Likert scale (1, 'not at all'; } 7 \text { 'very much'). } \\
\text { We found good concurrent validity of the ESM threat anticipation item with anxious mood ( } r=0.49, p< \\
\text { 0.001), which has been previously reported to be closely linked to threat anticipation (Freeman } \text { et al. 2013). }\end{array}$ \\
\hline $\begin{array}{l}\text { Psychotic } \\
\text { experiences }\end{array}$ & $\begin{array}{l}\text { The ESM psychosis measure was used to assess intensity of psychotic experiences. It consists of eight items } \\
\text { (i.e. 'I feel paranoid', 'I feel unreal', 'I hear things that aren't really there', 'I see things that aren't really } \\
\text { there', 'I can't get these thoughts out of my head', 'My thoughts are influenced by others', 'It's hard to } \\
\text { express my thoughts in words', 'I feel like I am losing control') rated on a 7-point Likert scale (Cronbach's } \\
\alpha=0.90 \text { ) (Myin-Germeys et al. 2005; Palmier-Claus et al. 2011). We observed good concurrent validity of } \\
\text { ESM measures of negative affect and psychotic experiences }(r=0.68, p<0.001)\end{array}$ \\
\hline
\end{tabular}

\footnotetext{
${ }^{a}$ ESM procedure: On each day over an assessment period of six consecutive days, the PsyMate ${ }^{\circledR}$ emitted ten 'beep' signals at random moments within set blocks of time. During an initial briefing session, participants were asked to stop their activity and answer questions about thoughts, feelings, behaviours, social situations, and neighbourhood surroundings each time the device emitted the beep signal. The ESM questionnaire was available to participants for the duration of 10 min after emission of the beep signal. Participants were contacted at least once during the assessment period to assess their adherence to instructions, identify any potential distress associated with the method, and maximize the number of observations per participant. At the end of the assessment period, participants' reactivity to, and compliance with, the method was examined in a debriefing session. Participants were required to provide valid responses to at least one-third of the emitted beeps to be included in the analysis (Delespaul et al. 2002).
} 
Table 3. Psychological mechanisms underlying sexual abuse in FEP, ARMS, and controls ${ }^{\mathrm{a}}$

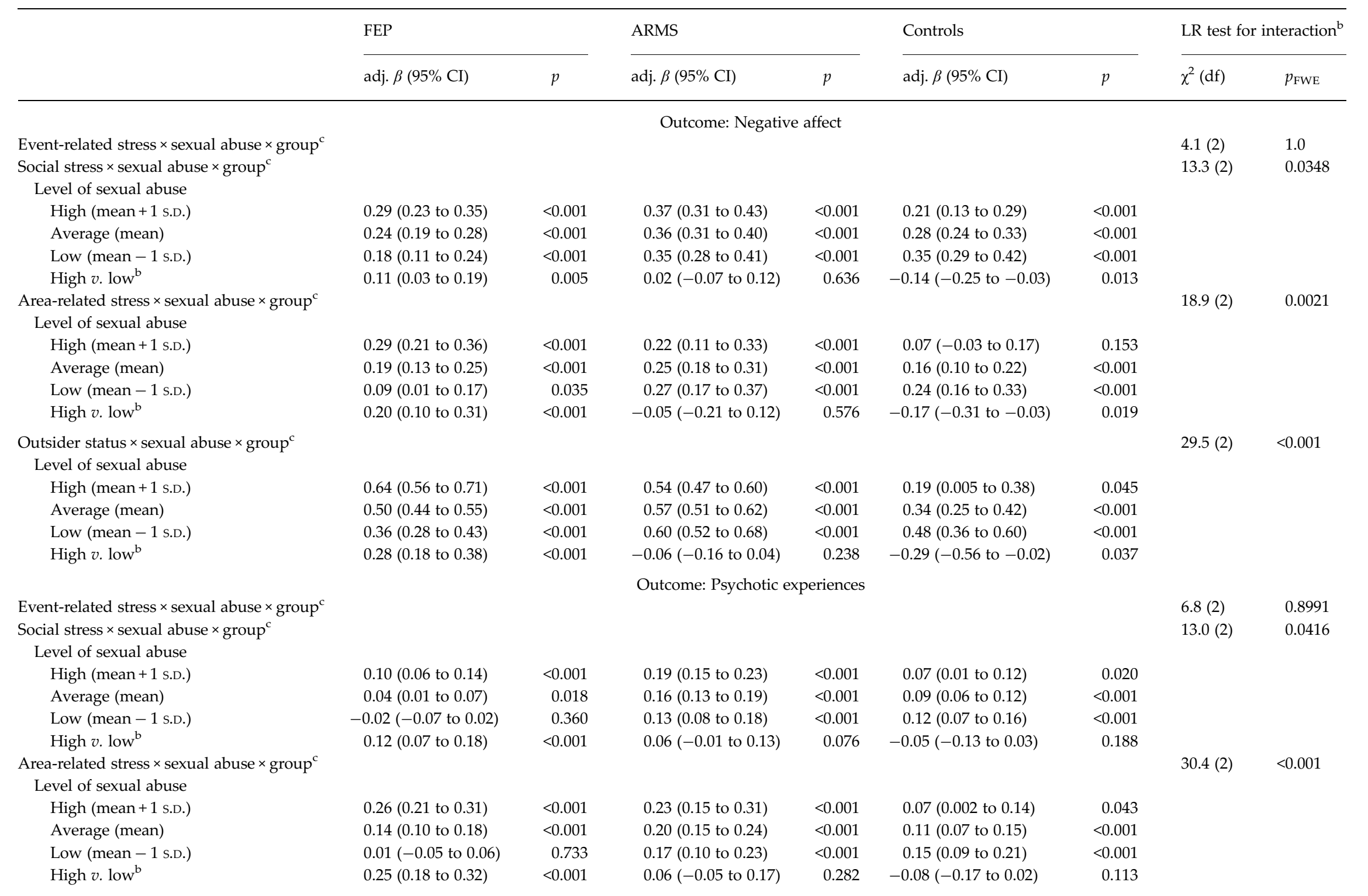


High (mean +1 s.D.)

Average (mean)

Low (mean -1 s.D.)

High $v$. low ${ }^{\mathrm{b}}$

Threat anticipation $\times$ sexual abuse $\times$ group ${ }^{c}$

Level of sexual abuse

High (mean +1 s.D.)

Average (mean)

Low (mean - 1 s.D.)

High $v$. low ${ }^{\mathrm{b}}$

\begin{abstract}
0.39 (0.34 to 0.45$)$
0.26 (0.23 to 0.30$)$

0.14 ( 0.08 to 0.19$)$
\end{abstract}

0.26 (0.19 to 0.33 )

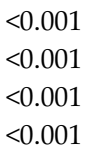

0.001

0.39 (0.34 to 0.43$)$

0.35 (0.31 to 0.39 )

0.32 ( 0.26 to 0.37$)$

0.07 (0.003 to 0.14$)$
$<0.001$
$<0.001$
$<0.001$
0.042

0.17 (0.04 to 0.30$)$

0.26 (0.20 to 0.31 )

0.34 ( 0.26 to 0.42$)$

-0.17 ( -0.36 to 0.02$)$
0.010

$<0.001$

$<0.001$

0.074

adj. $\beta$, Standardized regression coefficients [continuous independent variables were standardized (mean=0, S.D. =1) for interpreting significant three-way interaction terms and examining the difference in associations between high (mean +1 S.D.), average (mean), and low (mean -1 s.D.) levels of abuse within and across groups (FEP, ARMS, controls)]; ARMS, At-Risk Mental State for psychosis; CI, confidence interval; df, degrees of freedom; FEP, first-episode psychosis; LR, likelihood ratio; $p_{\mathrm{FWE}}$, family-wise error-corrected $p$ values were computed by multiplying the unadjusted $p$ value by the total number of tests to adjust significance levels of likelihood ratio tests for three-way interactions; S.D., standard deviation.

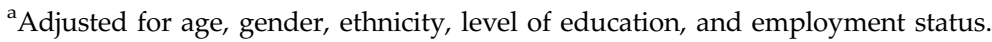

${ }^{\mathrm{b}}$ Difference in associations between those exposed to high $v$. low levels of sexual abuse across groups ( $\Delta$ high $v$. low):

$\Delta$ high v. low abuse across groups

Social stress

Area-related stress

Outsider status

Threat anticipation

$\Delta$ high v. low abuse across groups Social stress

Area-related stress

\begin{abstract}
$$
\text { FEP } v \text {. controls }
$$

\begin{tabular}{ll}
\hline adj. $\beta(95 \% \mathrm{CI})$ & $p$ \\
& \\
$0.25(0.12$ to 0.39$)$ & $<0.0005$ \\
$0.37(0.20$ to 0.55$)$ & $<0.0005$ \\
$0.57(0.28$ to 0.86$)$ & $<0.0005$
\end{tabular}

0.29 (0.25 to 0.33 )

$0.25(0.21$ to 0.29$)$

$<0.001$

$<0.001$

$<0.001$

$0.57(0.28$
\end{abstract}

$0.27(0.23$ to 0.32$)$

0.21 (0.18 to 0.25$)$

0.15 ( 0.10 to 0.20$)$

$<0.001$

0.11 (0.04 to 0.19$)$

0.17 (0.13 to 0.21$)$

0.004

$<0.001$

$<0.001 \quad 0.23$ (0.16 to 0.29$) \quad<0.00$

\begin{tabular}{|c|c|}
\hline \multicolumn{2}{|c|}{ ARMS $v$. controls } \\
\hline \multicolumn{2}{|c|}{ Outcome: negative affect } \\
\hline 0.16 (0.02 to 0.31$)$ & 0.028 \\
\hline $0.12(-0.09$ to 0.34$)$ & 0.268 \\
\hline $0.23(-0.06$ to 0.52$)$ & 0.120 \\
\hline \multicolumn{2}{|c|}{ Outcome: psychotic experiences } \\
\hline $0.11(0.01$ to 0.21$)$ & 0.032 \\
\hline $0.14(-0.01$ to 0.29$)$ & 0.065 \\
\hline $0.24(0.04$ to 0.44$)$ & 0.017 \\
\hline $0.23(0.10$ to 0.36$)$ & $<0.0005$ \\
\hline
\end{tabular}

\begin{tabular}{cc}
\multicolumn{2}{c}{ FEP $v$. ARMS } \\
\hline adj. $\beta(95 \%$ CI $)$ & $p$ \\
$0.09(-0.03$ to 0.21$)$ & 0.147 \\
$0.25(0.06$ to 0.44$)$ & 0.012 \\
$0.34(0.20$ to 0.48$)$ & $<0.0005$ \\
& \\
$0.06(-0.02$ to 0.15$)$ & 0.147 \\
$0.19(0.06$ to 0.32$)$ & 0.005 \\
$0.19(0.09$ to 0.29$)$ & $<0.0005$ \\
$-0.03(-0.12$ to 0.05$)$ & 0.454
\end{tabular}

${ }^{\mathrm{c}}$ Three-way interaction as included in the following model (with $y_{\mathrm{ij}}$ for negative affect or psychotic experiences as outcome variable):

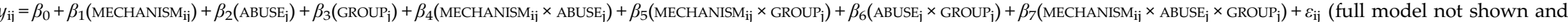
available upon request).

$\begin{array}{lccccc}0.18(0.08 \text { to } 0.27) & <0.0005 & 0.11(0.01 \text { to } 0.21) & 0.032 & 0.06(-0.02 \text { to } 0.15) & 0.147 \\ 0.33(0.21 \text { to } 0.45) & <0.0005 & 0.14(-0.01 \text { to } 0.29) & 0.065 & 0.19(0.06 \text { to } 0.32) & 0.005 \\ 0.43(0.23 \text { to } 0.63) & <0.0005 & 0.24(0.04 \text { to } 0.44) & 0.017 & 0.19(0.09 \text { to } 0.29) & <0.0005 \\ 0.20(0.07 \text { to } 0.33) & 0.002 & 0.23(0.10 \text { to } 0.36) & <0.0005 & -0.03(-0.12 \text { to } 0.05) & 0.454\end{array}$


negative affect (see Supplementary Fig. S1 $a-c$, explanatory notes). Similarly, social stress (adj. $\beta_{\text {high } v \text {. low }}=$ $0.12, p<0.001$ ), area-related stress (adj. $\beta_{\text {high }} v$. low $=$ $0.25, p<0.001$ ), outsider status (adj. $\beta_{\text {high } v \text {. low }}=0.26$, $p<0.001$ ) and threat anticipation (adj. $\beta_{\text {high } v \text {. low }}=$ $0.09, p=0.003$ ) were associated with (ii) more intense psychotic experiences in FEP individuals exposed to high $v$. low levels of sexual abuse (see Supplementary Fig. $51 d-g$, explanatory notes).

\section{ARMS (H1)}

Experiences of outsider status (adj. $\beta_{\text {high } v \text {. low }}=0.07$, $p=0.042$ ) and enhanced threat anticipation (adj. $\beta_{\text {high }}$ $v$. low $=0.12, p<0.001$ ) were associated with more intense psychotic experiences in ARMS exposed to high levels of sexual abuse than ARMS exposed to low levels of sexual abuse. There was no evidence that the associations of other putative psychological mechanisms with (i) negative affect and (ii) psychotic experiences were greater in ARMS exposed to high $v$. low levels of sexual abuse (see Supplementary Fig. S1 $a-g$, explanatory notes).

\section{Controls (H1)}

In contrast to FEP (and, in part, ARMS) individuals, in controls exposed to high levels of sexual abuse, social stress (adj. $\beta_{\text {high } v \text {. low }}=-0.14, p=0.013$ ), area-related stress (adj. $\beta_{\text {high } v \text {. low }}=-0.17, p=0.019$ ) and experiences of outsider status (adj. $\beta_{\text {high } v \text {. low }}=-0.29, p=0.037$ ) were associated with less intense negative affect, as well as enhanced threat anticipation with less intense psychotic experiences (adj. $\beta_{\text {high } v \text {. low }}=-0.11, p=0.047$ ), than in controls exposed to low levels of sexual abuse (see Supplementary Fig. S1 $a-g$, explanatory notes).

\section{Group comparison (H2)}

When we examined differences in the magnitude of associations of putative psychological mechanisms with (i) negative affect and (ii) psychotic experiences between those exposed to high $v$. low levels of sexual abuse across groups, we consistently observed marked differences across FEP and controls and, less consistent and marked, ARMS and controls (see Table 3, note c; Supplementary Fig. S1, explanatory notes). So for example, there was evidence that the difference in emotional reactivity to social stress between those exposed to high $v$. low levels of sexual abuse significantly varied across FEP $v$. controls (adj. $\beta_{\Delta \text { high } v \text {. low }}$ $=0.25, p<0.0005)$ and ARMS $v$. controls (adj. $\beta_{\Delta \text { high } v}$. low $=0.16, p=0.028$ ); also, the difference in associations of social stress and psychotic experiences between those exposed to high $v$. low levels of sexual abuse across groups was greatest in FEP $v$. controls (adj.
$\beta_{\Delta \text { high } v \text {. low }}=0.18, p<0.0005$ ), followed by ARMS $v$. controls (adj. $\beta_{\Delta \text { high } v \text {. low }}=0.11, p=0.032$ ). When we further compared FEP and ARMS, differences in associations of area-related stress, outsider status and (i) negative affect and (ii) psychotic experiences between those exposed to high $v$. low levels of sexual abuse were greater in FEP than in ARMS.

\section{Psychological mechanisms underlying physical abuse in FEP, ARMS, and controls}

We found no interaction effects of event-related stress $\times$ physical abuse $\times$ group, social stress $\times$ physical abuse $\times$ group, area-related stress $\times$ physical abuse $\times$ group, and outsider status $\times$ physical abuse $\times$ group on (i) negative affect and (ii) psychotic experiences (see Table 4). However, an interaction effect of threat anticipation $\times$ physical abuse $\times$ group on psychotic experiences (see Supplementary Fig. S2) indicated that enhanced threat anticipation was associated with more intense psychotic experiences in ARMS individuals exposed to high $v$. low levels of physical abuse (adj. $\beta_{\text {high } v \text {. low }}=0.22, p<$ 0.001 ). In FEP (adj. $\beta_{\text {high } v \text {. low }}=0.04, p=0.286$ ) and controls (adj. $\beta_{\text {high } v \text {. low }}=-0.03, p=0.716$ ), this association was similar in those with high $v$. low levels of physical abuse.

\section{Psychological mechanisms underlying emotional abuse in FEP, ARMS, and controls}

There was no evidence that associations between event-related stress, social stress, area-related stress, outsider status and (i) negative affect and (ii) psychotic experiences were modified by childhood emotional abuse in FEP, ARMS, and controls (see Table 5). However, we found an interaction effect of threat anticipation $\times$ emotional abuse $\times$ group (see Supplementary Fig. S3). This indicated that enhanced threat anticipation was associated with more psychotic experiences in ARMS individuals exposed to high $v$. low levels of emotional abuse (adj. $\beta_{\text {high } v \text {. low }}=0.20, p<0.001$ ), but neither in FEP individuals (adj. $\beta_{\text {high } v \text {. low }}=-0.03, p=0.392$ ) nor controls (adj. $\beta_{\text {high } v \text {. low }}=0.02, p=0.709$ ) with high and low levels of emotional abuse.

\section{Discussion \\ Principal findings}

Using an experience sampling design, this study found strong and consistent evidence that various forms of minor interpersonal and environmental stress in daily life (i.e. social stress, outsider status, area-related stress) were associated with both elevated negative affect and more intense psychotic experiences in FEP individuals exposed to high $v$. low levels of childhood sexual 
Table 4. Psychological mechanisms underlying physical abuse in FEP, ARMS, and controls

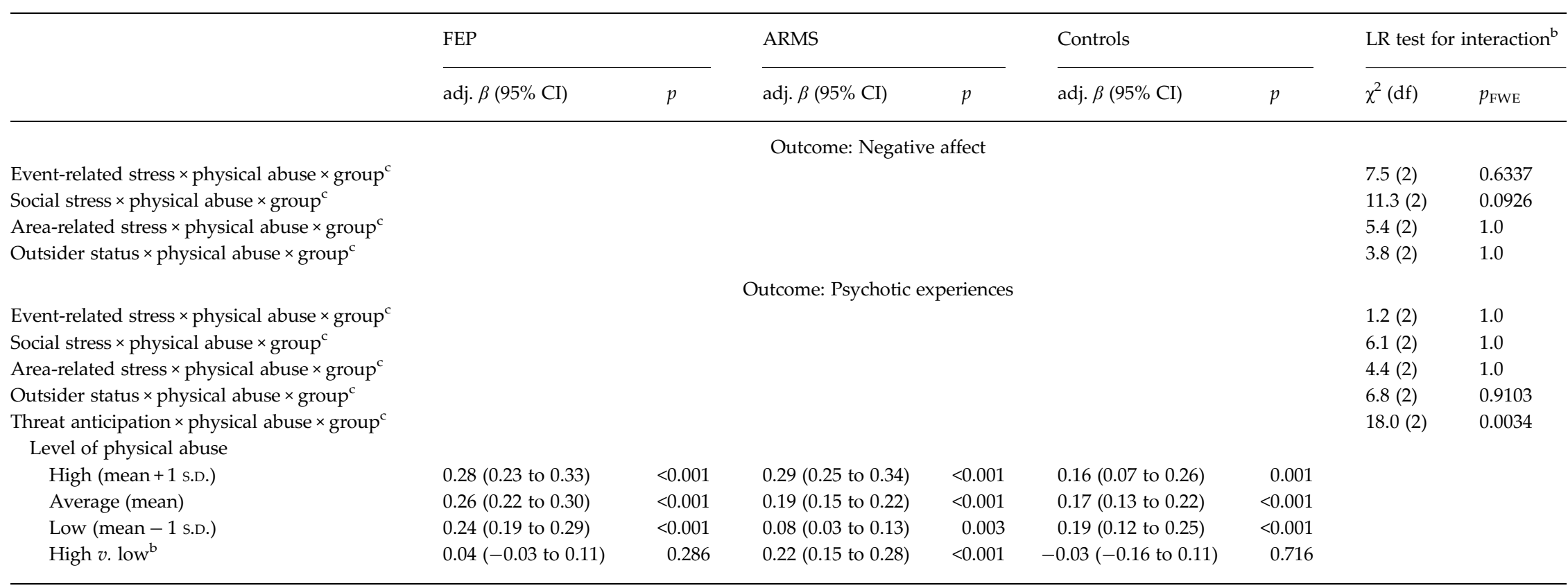

adj. $\beta$, Standardized regression coefficients [continuous independent variables were standardized (mean=0, S.D. $=1$ ) for interpreting significant three-way interaction terms and examining the difference in associations between high (mean +1 S.D.), average (mean), and low (mean -1 s.D.) levels of abuse within and across groups (FEP, ARMS, controls)] ARMS, At-Risk Mental State for psychosis; CI, confidence interval; df, degrees of freedom; FEP, first-episode psychosis; LR, likelihood ratio; $p_{\mathrm{FWE}}$, family-wise error-corrected $p$ values were computed by multiplying the unadjusted $p$ value by the total number of tests to adjust significance levels of likelihood ratio tests for three-way interactions; S.D., standard deviation.

${ }^{a}$ Adjusted for age, gender, ethnicity, level of education, and employment status.

${ }^{\mathrm{b}}$ Difference in associations between those exposed to high $v$. low levels of physical abuse across groups ( $\Delta$ high $v$. low):

FEP v. controls

adj. $\beta(95 \% \mathrm{CI}) \quad p$

$\Delta$ high v. low abuse across groups

Threat anticipation
$0.07(-0.09$ to 0.22$)$

0.395
ARMS v. controls

adj. $\beta(95 \% \mathrm{CI}) \quad p$
Outcome: psychotic experiences

FEP $v$. ARMS

adj. $\beta(95 \% \mathrm{CI})$

$<0.0005$

${ }^{\mathrm{c}}$ Three-way interaction as included in the following model (with $y_{\mathrm{ij}}$ for negative affect or psychotic experiences as outcome variable):

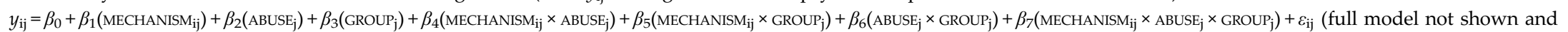
available upon request). 
Table 5. Psychological mechanisms underlying emotional abuse in FEP, ARMS, and controls ${ }^{\mathrm{a}}$

\begin{tabular}{|c|c|c|c|c|c|c|c|c|}
\hline & \multicolumn{2}{|l|}{ FEP } & \multicolumn{2}{|l|}{ ARMS } & \multicolumn{2}{|l|}{ Controls } & \multicolumn{2}{|c|}{$\begin{array}{l}\text { LR test for } \\
\text { interaction }^{\mathrm{b}}\end{array}$} \\
\hline & adj. $\beta(95 \% \mathrm{CI})$ & $p$ & adj. $\beta(95 \% \mathrm{CI})$ & $p$ & adj. $\beta(95 \% \mathrm{CI})$ & $p$ & $\chi^{2}(\mathrm{df})$ & $p_{\mathrm{FWE}}$ \\
\hline \multicolumn{9}{|c|}{ Outcome: Negative affect } \\
\hline Event-related stress $\times$ emotional abuse $\times$ group $^{c}$ & & & & & & & $9.9(2)$ & 0.1898 \\
\hline Social stress $\times$ emotional abuse $\times$ group $^{c}$ & & & & & & & $4.7(2)$ & 1.0 \\
\hline Area-related stress $\times$ emotional abuse $\times$ group $^{c}$ & & & & & & & $1.8(2)$ & 1.0 \\
\hline Outsider status $\times$ emotional abuse $\times$ group $^{c}$ & & & & & & & $7.5(2)$ & 0.6248 \\
\hline \multicolumn{9}{|c|}{ Outcome: Psychotic experiences } \\
\hline Event-related stress $\times$ emotional abuse $\times$ group $^{c}$ & & & & & & & $8.5(2)$ & 0.3819 \\
\hline Social stress $\times$ emotional abuse $\times$ group $^{c}$ & & & & & & & $0.4(2)$ & 1.0 \\
\hline Area-related stress $\times$ emotional abuse $\times$ group $^{c}$ & & & & & & & $7.1(2)$ & 0.7843 \\
\hline Outsider status $\times$ emotional abuse $\times$ group ${ }^{c}$ & & & & & & & $8.0(2)$ & 0.5026 \\
\hline Threat anticipation $\times$ emotional abuse $\times$ group $^{c}$ & & & & & & & $22.5(2)$ & 0.0003 \\
\hline \multicolumn{9}{|l|}{ Level of emotional abuse } \\
\hline High (mean + 1 s.D.) & $0.24(0.19$ to 0.30$)$ & $<0.001$ & $0.25(0.21$ to 0.28$)$ & $<0.001$ & $0.19(0.10$ to 0.29$)$ & $<0.001$ & & \\
\hline Average (mean) & $0.26(0.22$ to 0.30$)$ & $<0.001$ & 0.15 (0.11 to 0.19$)$ & $<0.001$ & $0.18(0.14$ to 0.23$)$ & $<0.001$ & & \\
\hline Low (mean - 1 s.D.) & $0.28(0.22$ to 0.34$)$ & $<0.001$ & $0.05(-0.01$ to 0.11$)$ & 0.106 & 0.17 (0.11 to 0.23$)$ & $<0.001$ & & \\
\hline High $v$. low ${ }^{\mathrm{b}}$ & $-0.03(-0.11$ to 0.04$)$ & 0.392 & $0.20(0.14$ to 0.25$)$ & $<0.001$ & $0.02(-0.10$ to 0.15$)$ & 0.709 & & \\
\hline
\end{tabular}

adj. $\beta$, standardized regression coefficients [continuous independent variables were standardized (mean =0, s.D. $=1$ ) for interpreting significant three-way interaction terms and examining the difference in associations between high (mean +1 S.D.), average (mean), and low (mean - 1 s.D.) levels of abuse within and across groups (FEP, ARMS, controls)]; ARMS, At-Risk Mental State for psychosis; CI, confidence interval; df, degrees of freedom; FEP, first-episode psychosis; LR, likelihood ratio; $p_{\mathrm{FWE}}$, family-wise error-corrected $p$ values were computed by multiplying the unadjusted $p$ value by the total number of tests to adjust significance levels of likelihood ratio tests for three-way interactions; S.D., standard deviation.

${ }^{a}$ Adjusted for age, gender, ethnicity, level of education, and employment status.

${ }^{b}$ Difference in associations between those exposed to high $v$. low levels of emotional abuse across groups ( $\Delta$ high $v$. low):

\section{FEP $v$. controls}

adj. $\beta(95 \% \mathrm{CI})$
ARMS v. controls

\begin{tabular}{l}
\hline adj. $\beta(95 \% \mathrm{CI}) \quad p$ \\
Outcome: psychotic experiences
\end{tabular}

FEP $v$. ARMS adj. $\beta(95 \% \mathrm{CI})$

$-0.23(-0.33$ to -0.13$)$
$-0.06(-0.20$ to 0.09$)$

$<0.0005$

\section{Troups}

Threat anticipation

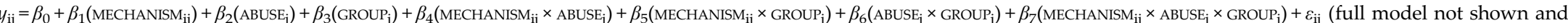
available upon request). 
abuse. The association between threat anticipation and psychotic experiences was also greater in FEP individuals exposed to high $v$. low levels of sexual abuse. Our findings further suggest that, controls exposed to high levels of sexual abuse were, by contrast, more resilient, with minor socio-environmental stressors being associated with less intense negative affect and enhanced threat anticipation with less intense psychotic experiences than in controls exposed to low levels of sexual abuse. ARMS individuals formed an intermediate group, with only some evidence of more intense psychotic experiences associated with experiences of outsider status and enhanced threat anticipation in those exposed. A less clear-cut pattern emerged from findings on putative psychological mechanisms underlying physical and emotional abuse. ARMS individuals, but not FEP individuals and controls, exposed to physical and emotional abuse reported more intense psychotic experiences in relation to enhanced threat anticipation.

\section{Comparison with previous research}

In recent years, it has been repeatedly proposed that exposure to trauma and abuse early in life may impact on the development of psychosis by increasing vulnerability to the negative effects of subsequent adversity via elevated stress sensitivity and enhanced threat anticipation as important psychological mechanisms on a socio-developmental pathway to psychosis (Morgan \& Hutchinson, 2010; Morgan et al. 2010, 2014). However, evidence in support of this proposition remained limited. We observed a consistent pattern of findings in FEP individuals that suggests exposure to sexual abuse may sensitize individuals to the negative effects of more minor adverse social contexts and experiences later in daily life, indexed by elevated sensitivity to social stress, area-related stress, and experiences of outsider status, as a potential psychological process associated with the development of psychotic experiences. Exposure to adverse social experiences such as childhood sexual abuse, which have recently been linked to increased striatal dopamine synthesis (Egerton et al. 2014) and involve the quality of interpersonal violence and threat, have been posited as having a particular relevance for, and specificity to, psychotic disorders (Harris, 1987; Bebbington et al. 2004; Morgan \& Hutchinson, 2010). Notably, exposure to childhood sexual abuse specifically increased sensitivity to interpersonal stress in daily life (i.e. unpleasant social situations, experiences of outsider status) but not event-related stress or daily hassles in our case sample. A similar pattern was evident in ARMS individuals, who reported more intense psychotic experiences in response to experiences of outsider status following exposure to high levels of sexual abuse. We may therefore speculate that one specific pathway for the impact of childhood sexual abuse on psychosis may be via heightened interpersonal sensitivity by creating an enduring sense of feeling vulnerable in the presence of others (Bell \& Freeman, 2014), which has been previously reported to be a relevant psychological mechanism in individuals with a psychotic disorder and ARMS (Bell \& Freeman, 2014). What is more, our findings extended beyond interpersonal sensitivity and also involved sensitivity to wider adverse socioenvironmental contexts in daily life (i.e. unpleasant neighbourhoods) and, as has been previously proposed, an enduring sense of anticipating further unpleasant events and threat (Corcoran et al. 2006; Bentall et al. 2009, 2014; Morgan et al. 2010; Freeman et al. 2013).

In contrast to our first hypothesis (of greater associations in those exposed within each group), we observed that social stress, area-related stress and experiences of outsider status were associated with less intense negative affect, as well as enhanced threat anticipation with a lower intensity of psychotic experiences in controls exposed to high levels of sexual abuse. Also, the difference in these associations between those exposed to high and low levels of abuse were not, as predicted, greater in FEP individuals than controls, as, by contrast, associations were reversed in controls. This is a striking finding, which strongly points toward controls with prior exposure to sexual abuse being less sensitive and, in fact, more resilient to socio-environmental stress in daily life. It links in with consistent evidence that a considerable proportion of individuals exposed to sexual abuse in childhood subsequently show resilience to psychopathology and positive psychosocial functioning in adolescence and adulthood (Collishaw et al. 2007; Jaffee et al. 2007; Rutter, 2007). Good quality interpersonal relationships have previously been found to be associated with resilience to the development of adult psychopathology in individuals exposed to severe sexual or physical abuse in childhood (Collishaw et al. 2007). Further, a recent systematic review by Gayer-Anderson \& Morgan (2013) reported increased social networks and support in controls than individuals with psychotic experiences or first-episode psychosis. Although tentative, one possibility therefore is that (better) access to, and good quality of, social networks and support may have enhanced interpersonal resilience to adverse social experiences (i.e. unpleasant social situations, experiences of outsider status) in daily life and, thereby, averted exposure to sexual abuse from exerting its detrimental effects in controls. Along similar lines, growing up in a positive home environment and low-crime, high-social cohesion neighbourhoods have been previously found 
to be associated with resilience in children exposed to childhood trauma (Jaffee et al. 2007; Rutter, 2007). There is also some evidence that resilience is associated with more rapid recovery from anticipation of threat (Tugade \& Fredrickson, 2004; Waugh et al. 2008). Genetic moderation of resilience to the environment may potentially explain further why controls responded differently to sexual abuse than FEP individuals (Rutter, 2007). While speculative, resilience to adverse socio-environmental contexts (i.e. area-related stress) and anticipation of threat, in interaction with (lower) polygenic risk, may in part account for our findings in controls exposed to high levels of sexual abuse. Viewed this way, ARMS individuals may, then, form an intermediate group of resilient and non-resilient individuals, for whom we found only some, limited evidence of elevated sensitivity to socio-environmental stress (i.e. experiences of outsider status) in those exposed to childhood sexual abuse at a group level. Given, further, a considerable proportion of ARMS individuals experience comorbid anxiety (Fusar-Poli et al. 2013b), possibly as a result of higher levels of emotional abuse (as observed in our sample), and anxiety is commonly considered to drive increased threat anticipation (Freeman et al. 2013), a specific affective pathway from emotional abuse via elevated anxiety and increased threat anticipation may crystallize in this group.

\section{Methodological considerations}

These findings should be viewed in the light of several potential methodological issues. First, we used the CTQ, a retrospective, self-report measure of childhood sexual, physical and emotional abuse. One common concern about retrospective measures of childhood trauma is that they may be susceptible to recall bias and affected by cognitive impairments or positive symptoms associated with psychotic disorder (Fisher et al. 2011; Susser \& Widom, 2012). ESM ratings of putative psychological mechanisms and psychotic experiences were also based on subjective self-report. However, good reliability and validity has recently been reported for retrospective self-reports of early experiences obtained from individuals with a psychotic disorder (Fisher et al. 2011). Similarly, the ESM has been found to be a reliable and valid assessment method in individuals with ARMS and psychotic disorder in previous studies (Myin-Germeys et al. 2001, 2005, 2009; Palmier-Claus et al. 2012). This allowed us to assess psychological mechanisms and psychotic experiences in the real world and in real time. In addition, we adopted a recently suggested approach to reducing recall bias by measuring childhood trauma before the outcome of interest (i.e. psychotic disorder) in the ARMS sample (Susser \& Widom, 2012) and moved beyond previous experience sampling research in restricting our sample of patients to those with a first episode of psychosis. Although not drug-naïve, this sample allowed us to minimize the impact of illness chronicity and other consequences of psychotic disorder, which may have affected findings from previous studies in patients with enduring psychosis (Lardinois et al. 2011). Coupled with our ARMS sample without any prior treatment with an antipsychotic for a psychotic episode, this provided evidence on childhood trauma and putative causal mechanisms prior to (i.e. during the prodromal period in (some of) the ARMS individuals) and at first onset of psychotic disorder. Second, ESM data collection is time intense and may be associated with assessment burden for participants. Therefore, we cannot rule out that selection bias may have occurred as a result of this. Third, cross-sectional modelling of experience sampling data did not allow us to systematically examine temporal priority of putative psychological mechanisms over psychotic experiences or other criteria for establishing causal relations. We therefore cannot rule out that the differences across groups may be explained by the different stages of early psychosis. Fourth, while the prevalence of sexual abuse was similar to what has been previously reported (Fisher et al. 2009; Pereda et al. 2009; Thompson et al. 2014), the number of participants reporting moderate or severe abuse was, in absolute terms, still relatively small (see Supplementary Table S1). This did not allow for probing findings further, for example, with regard to potential gender differences that may have operated on putative psychological mechanisms given the prevalence and impact of childhood trauma on later psychopathology has been previously found to differ between men and women (e.g. Fisher et al. 2009; Pereda et al. 2009). Last, the number of tests for assessing three-way interactions that we conducted for each type of abuse and psychological mechanism may have inflated Type I error. However, we adjusted significance levels of these tests and only considered $p_{\mathrm{FWE}}$ for assessing evidence of three-way interactions. In addition, for statistically significant three-way interactions, effect sizes for the difference in associations between individuals exposed to high and low levels of abuse within and across groups were overall of small to moderate magnitude (in particular, within FEP and when comparing FEP and controls), which reflects a substantial, cumulative impact of abuse on putative psychological mechanisms in daily life.

\section{Conclusions}

Our findings suggest that enhanced threat anticipation and elevated sensitivity to socio-environmental stress 
in daily life are important psychological processes underlying the association between childhood sexual abuse and psychosis. Some initial evidence of specificity emerged for the impact of socio-environmental exposures involving the quality of interpersonal threat such as childhood sexual abuse via pathways through heightened interpersonal sensitivity in daily life. At the same time, findings in our control sample tentatively suggest interpersonal resilience and, more broadly, resilience to adverse social contexts may potentially take on the role of protective factors associated with the development of psychotic experiences. More generally, this supports the proposition that specific risk and protective factors of psychosis emerge over time, with distal factors exerting their effects by increasing vulnerability or resilience to the effects of more proximal exposures via specific psychological mechanisms. We now need to develop and evaluate ecological momentary interventions that directly target these mechanisms and reduce the intensity of psychotic experiences in daily life (Reininghaus et al. 2016b), with the goal of promoting resilience to, and preventing onset of, psychosis.

\section{Supplementary material}

For supplementary material accompanying this article visit http://dx.doi.org/10.1017/S003329171600146X.

\section{Acknowledgements}

National Institute for Health Research (NIHR) NIHR-PDF-201104065; Netherlands Organisation for Scientific Research - 451-13-022; Wellcome Trust WT087417; European Community's Seventh Framework Program - HEALTH-F2-2009-241909; NIHR Biomedical Research Centre for Mental Health. This work was supported by a Postdoctoral Research Fellowship of the UK National Institute for Health Research (NIHR) (grant no. NIHR-PDF-201104065) to U.R. U.R. is further supported by a Veni grant from the Netherlands Organisation for Scientific Research (grant no. 451-13-022). The work was also supported by funding from the Wellcome Trust (WT087417) to C.M. and is an approved add-on study of the 'The European Network of National Networks studying Gene-Environment Interactions in Schizophrenia' (EU-GEI), which is supported by funding from the European Union [European Community's Seventh Framework Programme (HEALTH-F2-2009-241909; Project EU-GEI)]. The authors acknowledge financial support from the NIHR Biomedical Research Centre for Mental Health at South London and Maudsley NHS Foundation Trust and King's College London. The views expressed are those of the authors and not necessarily those of the NHS, the NIHR or the Department of Health.

\section{Declaration of Interest}

None.

\section{References}

Aiken L, West S (1991). Multiple Regression: Testing and Interpreting Interactions. Sage: Newbury Park, CA.

Bebbington P, Nayani T (1995). The Psychosis Screening Questionnaire. International Journal of Methods in Psychiatric Research 5, 11-19.

Bebbington PE, Bhugra D, Brugha T, Singleton N, Farrell M, Jenkins R, Lewis G, Meltzer H (2004). Psychosis, victimisation and childhood disadvantage: evidence from the second British National Survey of Psychiatric Morbidity. British Journal of Psychiatry 185, 220-226.

Bell V, Freeman D (2014). A pilot trial of cognitive behavioural therapy for interpersonal sensitivity in individuals with persecutory delusions. Journal of Behavior Therapy and Experimental Psychiatry 45, 441-446.

Bentall RP, de Sousa P, Varese F, Wickham S, Sitko K, Haarmans M, Read J (2014). From adversity to psychosis: pathways and mechanisms from specific adversities to specific symptoms. Social Psychiatry and Psychiatric Epidemiology 49, 1011-1022.

Bentall RP, Rowse G, Kinderman P, Blackwood N, Howard R, Moore R, Cummins S, Corcoran R (2008). Paranoid delusions in schizophrenia spectrum disorders and depression: the transdiagnostic role of expectations of negative events and negative self-esteem. Journal of Nervous and Mental Disease 196, 375-383.

Bentall RP, Rowse G, Shryane N, Kinderman P, Howard R, Blackwood N, Moore R, Corcoran R (2009). The cognitive and affective structure of paranoid delusions: a transdiagnostic investigation of patients with schizophrenia spectrum disorders and depression. Archives of General Psychiatry 66, 236-247.

Bernstein DP, Fink L (1998). Childhood Trauma Questionnaire: a Retrospective Self-report Manual. The Psychological Corporation: San Antonio, Texas.

Cohen J, Cohen P, West S, Aiken L (2003). Applied Multiple Regression/Correlation Analysis for the Behavioral Sciences. Erlbaum: Mahwah, NJ.

Collishaw S, Pickles A, Messer J, Rutter M, Shearer C, Maughan B (2007). Resilience to adult psychopathology following childhoodmaltreatment: evidence from a community sample. Child Abuse \& Neglect 31, 211-229.

Corcoran R, Cummins S, Rowse G, Moore R, Blackwood N, Howard R, Kinderman P, Bentall RP (2006). Reasoning under uncertainty: heuristic judgments in patients with persecutory delusions or depression. Psychological Medicine 36, 1109-1118.

Dawson J, Richter A (2006). Probing three-way interactions in moderated multiple regression: development and 
application of a slope difference test. Journal of Applied Psychology 91, 917-926.

Delespaul P, deVries M, van Os J (2002). Determinants of occurrence and recovery from hallucinations in daily life. Social Psychiatry and Psychiatric Epidemiology 37, 97-104.

Egerton A, Valmaggia L, Howes O, Day F, Chaddock CA, Allen P, Winton-Brown TT, Bloomfield M, Bhattacharyya S, Chilcott J, Lappin J, Murray RM, McGuire P (2014). Effect of childhood adversity on brain dopamine function in adulthood. European Psychopharmacology 24 (Suppl. 2), S505.

European Network of National Networks studying Gene-Environment Interactions in Schizophrenia (EU-GEI) (2014). Identifying gene-environment interactions in schizophrenia: contemporary challenges for integrated, large-scale investigations. Schizophrenia Bulletin 40, 729-736.

First MB, Spitzer RL, Gibbon M, Williams JBW (2002). Structured Clinical Interview for DSM-IV-TR Axis I Disorders. Biometrics Research, New York State Psychiatric Institute: New York.

Fisher H, Morgan C, Dazzan P, Craig TK, Morgan K, Hutchinson G, Jones PB, Doody GA, Pariante C, McGuffin P, Murray RM, Leff J, Fearon P (2009). Gender differences in the association between childhood abuse and psychosis. British Journal of Psychiatry 194, 319-325.

Fisher HL, Craig TK, Fearon P, Morgan K, Dazzan P, Lappin J, Hutchinson G, Doody GA, Jones PB, McGuffin P, Murray RM, Leff J, Morgan C (2011). Reliability and comparability of psychosis patients' retrospective reports of childhood abuse. Schizophrenia Bulletin 37, 546-553.

Freeman D, Dunn G, Fowler D, Bebbington P, Kuipers E, Emsley R, Jolley S, Garety P (2013). Current paranoid thinking in patients with delusions: the presence of cognitive-affective biases. Schizophrenia Bulletin 39, 1281-1287.

Fusar-Poli P, Borgwardt S, Bechdolf A, Addington J, Riecher-Rossler A, Schultze-Lutter F, Keshavan M, Wood S, Ruhrmann S, Seidman LJ, Valmaggia L, Cannon T, Velthorst E, De Haan L, Cornblatt B, Bonoldi I, Birchwood M, McGlashan T, Carpenter W, McGorry P, Klosterkotter J, McGuire P, Yung A (2013a). The psychosis high-risk state: a comprehensive state-of-the-art review. JAMA Psychiatry 70, 107-120.

Fusar-Poli P, Byrne M, Badger S, Valmaggia LR, McGuire PK (2013b). Outreach and support in south London (OASIS), 2001-2011: ten years of early diagnosis and treatment for young individuals at high clinical risk for psychosis. European Psychiatry 28, 315-326.

Gayer-Anderson C, Morgan C (2013). Social networks, support and early psychosis: a systematic review. Epidemiology and Psychiatric Sciences 22, 131-146.

Gevonden MJ, Myin-Germeys I, van den Brink W, van Os J, Selten JP, Booij J (2015). Psychotic reactions to daily life stress and dopamine function in people with severe hearing impairment. Psychological Medicine 45, 1665-1674.

Glaser JP, van Os J, Portegijs PJ, Myin-Germeys I (2006). Childhood trauma and emotional reactivity to daily life stress in adult frequent attenders of general practitioners. Journal of Psychosomatic Research 61, 229-236.
Goldman HH, Skodol AE, Lave TR (1992). Revising axis V for DSM-IV: a review of measures of social functioning. American Journal of Psychiatry 149, 1148-1156.

Harris TO (1987). Recent developments in the study of life events in relation to psychiatric and physical disorders. In Psychiatric Epidemiology (ed. B. Cooper), pp. 81-103. Croom Helm: London.

Howes OD, Murray RM (2014). Schizophrenia: an integrated sociodevelopmental-cognitive model. Lancet 383, 16771687.

Jaffee SR, Caspi A, Moffitt TE, Polo-Tomas M, Taylor A (2007). Individual, family, and neighborhood factors distinguish resilient from non-resilient maltreated children: a cumulative stressors model. Child Abuse E Neglect 31, 231-253.

Kirkbride JB, Jones PB, Ullrich S, Coid JW (2014). Social deprivation, inequality, and the neighborhood-level incidence of psychotic syndromes in East London. Schizophrenia Bulletin 40, 169-180.

Klosterkotter J, Schultze-Lutter F, Bechdolf A, Ruhrmann S (2011). Prediction and prevention of schizophrenia: what has been achieved and where to go next? World Psychiatry 10, 165-174.

Lardinois M, Lataster T, Mengelers R, Van Os J, Myin-Germeys I (2011). Childhood trauma and increased stress sensitivity in psychosis. Acta Psychiatrica Scandinavica 123, 28-35.

Mallet R (1997). Sociodemographic Schedule. Section of Social Psychiatry, Institute of Psychiatry: London, UK.

Matheson SL, Shepherd AM, Pinchbeck RM, Laurens KR, Carr VJ (2013). Childhood adversity in schizophrenia: a systematic meta-analysis. Psychological Medicine 43, 225-238.

Maxwell E (1992). Manual for the Family Interview of Genetic Studies (FIGS). Center for Collaborative Genetic Studies on Mental Disorders: St. Louis.

McGuffin P, Farmer A, Harvey I (1991). A polydiagnostic application of operational criteria in studies of psychotic illness. Development and reliability of the OPCRIT system. Archives of General Psychiatry 48, 764-770.

Mills JG (2014). Defining the Prevalence of Subjects at Ultra High Risk of Developing Psychosis in the General Population. King's College London: London.

Morgan C, Charalambides M, Hutchinson G, Murray RM (2010). Migration, ethnicity, and psychosis: toward a sociodevelopmental model. Schizophrenia Bulletin 36, 655664.

Morgan C, Fisher H (2007). Environment and schizophrenia: environmental factors in schizophrenia: childhood trauma a critical review. Schizophrenia Bulletin 33, 3-10.

Morgan C, Hutchinson G (2010). The socio-developmental origins of psychosis. In Principles of Social Psychiatry (ed. C. Morgan and D. Bhugra), pp. 193-213. John Wiley \& Sons, Ltd.: Chichester, UK.

Morgan C, Reininghaus U, Fearon P, Hutchinson G, Morgan K, Dazzan P, Boydell J, Kirkbride JB, Doody GA, Jones PB, Murray RM, Craig T (2014). Modelling the interplay between childhood and adult adversity in pathways to psychosis: initial evidence from the AESOP study. Psychological Medicine 44, 407-419. 
Myin-Germeys I, Birchwood M, Kwapil T (2011). From environment to therapy in psychosis: a real-world momentary assessment approach. Schizophrenia Bulletin 37, 244-247.

Myin-Germeys I, Delespaul P, van Os J (2005). Behavioural sensitization to daily life stress in psychosis. Psychological Medicine 35, 733-741.

Myin-Germeys I, Oorschot M, Collip D, Lataster J, Delespaul P, van Os J (2009). Experience sampling research in psychopathology: opening the black box of daily life. Psychological Medicine 39, 1533-1547.

Myin-Germeys I, van Os J, Schwartz JE, Stone AA, Delespaul PA (2001). Emotional reactivity to daily life stress in psychosis. Archives of General Psychiatry 58, 11371144.

Palmier-Claus JE, Dunn G, Lewis SW (2012). Emotional and symptomatic reactivity to stress in individuals at ultra-high risk of developing psychosis. Psychological Medicine 42, 1003-1012.

Palmier-Claus JE, Myin-Germeys I, Barkus E, Bentley L, Udachina A, Delespaul PA, Lewis SW, Dunn G (2011). Experience sampling research in individuals with mental illness: reflections and guidance. Acta Psychiatrica Scandinavica 123, 12-20.

Pereda N, Guilera G, Forns M, Gómez-Benito J (2009). The prevalence of child sexual abuse in community and student samples: a meta-analysis. Clinical Psychology Review 29, 328338.

Read J, van Os J, Morrison AP, Ross CA (2005). Childhood trauma, psychosis and schizophrenia: a literature review with theoretical and clinical implications. Acta Psychiatrica Scandinavica 112, 330-350.

Reininghaus U, Bohnke JR, Hosang G, Farmer A, Burns T, McGuffin P, Bentall R (2016a). Evaluation of the validity and utility of a dimensional approach to the diagnosis of psychosis. British Journal of Psychiatry. Published online: 17 March 2016 doi:10.1192/bjp.bp.115.167882.

Reininghaus U, Depp C, Myin-Germeys I (2016b). Ecological interventionist causal models in psychosis: targeting psychological mechanisms in daily life. Schizophrenia Bulletin 42, 264-269.

Reininghaus U, Kempton MJ, Valmaggia L, Craig TKJ, Garety P, Onyejiaka A, Gayer-Anderson C, So SH, Hubbard K, Beards S, Dazzan D, Pariante C, Mondelli V, Fisher HL, Mills JG, Viechtbauer W, McGuire P, van Os J, Murray RM, Wykes T, Myin-Germeys I, Morgan C (2016c). Stress sensitivity, aberrant salience, and threat anticipation in early psychosis: an experience sampling study. Schizophrenia Bulletin. Published online: 1 February 2016 doi:10.1093/schbul/sbv190.

Rutter M (2007). Resilience, competence, and coping. Child Abuse \& Neglect 31, 205-209.

Ryan JJ, Weilage ME, Spaulding WD (1999). Accuracy of the seven subtest WAIS-R short form in chronic schizophrenia. Schizophrenia Research 39, 79-83.

Scher CD, Stein MB, Asmundson GJ, McCreary DR, Forde DR (2001). The childhood trauma questionnaire in a community sample: psychometric properties and normative data. Journal of Traumatic Stress 14, 843-857.

Schultze-Lutter F, Klosterkötter J, Picker H, Steinmeyer EM, Ruhrmann S (2007). Predicting first-episode psychosis by basic symptom criteria. Clinical Neuropsychiatry 4, 11-22.

Schultze-Lutter F, Ruhrmann S, Berning J, Maier W, Klosterkotter J (2010). Basic symptoms and ultrahigh risk criteria: symptom development in the initial prodromal state. Schizophrenia Bulletin 36, 182-191.

Schultze-Lutter F, Ruhrmann S, Fusar-Poli P, Bechdolf A, Schimmelmann BG, Klosterkotter J (2012). Basic symptoms and the prediction of first-episode psychosis. Current Pharmaceutical Design 18, 351-357.

Shiffman S, Stone AA, Hufford MR (2008). Ecological momentary assessment. Annual Review of Clinical Psychology 4, 1-32.

StataCorp. (2013). Stata Statistical Software: Release 13. StataCorp LP: College Station, TX.

Susser E, Widom CS (2012). Still searching for lost truths about the bitter sorrows of childhood. Schizophrenia Bulletin 38, 672-675.

Thompson A, Nelson B, Yuen H, Lin A, Amminger G, McGorry P, Wood S, Yung A (2014). Sexual trauma increases the risk of developing psychosis in an ultra high-risk 'prodromal' population. Schizophrenia Bulletin 40, 697-706.

Tugade MM, Fredrickson BL (2004). Resilient individuals use positive emotions to bounce back from negative emotional experiences. Journal of Personality and Social Psychology 86, 320-333.

Varese F, Smeets F, Drukker M, Lieverse R, Lataster T, Viechtbauer W, Read J, van Os J, Bentall RP (2012). Childhood adversities increase the risk of psychosis: a meta-analysis of patient-control, prospective- and crosssectional cohort studies. Schizophrenia Bulletin 38, 661-671.

Waugh CE, Fredrickson BL, Taylor SF (2008). Adapting to life's slings and arrows: individual differences in resilience when recovering from an anticipated threat. Journal of Research Personality 42, 1031-1046.

WHO (1992). The ICD-10 Classification of Mental and Behavioural Disorders: Clinical Descriptions and Diagnostic Guidelines. World Health Organization: Geneva.

Wichers M, Schrijvers D, Geschwind N, Jacobs N, Myin-Germeys I, Thiery E, Derom C, Sabbe B, Peeters F, Delespaul P, van Os J (2009). Mechanisms of geneenvironment interactions in depression: evidence that genes potentiate multiple sources of adversity. Psychological Medicine 39, 1077-1086.

Wright KD, Asmundson GJ, McCreary DR, Scher C, Hami S, Stein MB (2001). Factorial validity of the Childhood Trauma Questionnaire in men and women. Depression and Anxiety 13, 179-183.

Yung AR, Yuen HP, McGorry PD, Phillips LJ, Kelly D, Dell'Olio M, Francey SM, Cosgrave EM, Killackey E, Stanford C, Godfrey K, Buckby J (2005). Mapping the onset of psychosis: the Comprehensive Assessment of At-Risk Mental States. Australian \& New Zealand Journal of Psychiatry 39, 964-971. 